\title{
TCF7L2 in mouse pancreatic beta cells plays a crucial role in glucose homeostasis by regulating beta cell mass
}

\author{
Iseki Takamoto $\cdot$ Naoto Kubota $\cdot$ Keizo Nakaya $\cdot$ Katsuyoshi Kumagai • \\ Shinji Hashimoto • Tetsuya Kubota • Mariko Inoue • Eiji Kajiwara • \\ Hisayuki Katsuyama • Atsushi Obata • Yoshitaka Sakurai • Masahiko Iwamoto • \\ Tadahiro Kitamura • Kohjiro Ueki • Takashi Kadowaki
}

Received: 5 August 2013 / Accepted: 11 November 2013 /Published online: 8 December 2013

(C) Springer-Verlag Berlin Heidelberg 2013

\begin{abstract}
Aims/hypothesis Common genetic variations of the transcription factor 7-like 2 gene (encoded by TCF7L2), one of the $\mathrm{T}$ cell factor/lymphoid enhancer-binding factor transcription factors for the converging wingless-type MMTV integration site family (Wnt)/ $\beta$-catenin signalling pathway, are known to be associated with type 2 diabetes. Individuals with at-risk alleles of TCF7L2 exhibit impaired insulin secretion. Although previous studies using animal models have revealed the existence of a relationship between the $\mathrm{Wnt} / \beta$-catenin signalling pathway and glucose homeostasis, it remains unclear whether TCF7L2 in the pancreatic beta cells might be causally involved in insulin secretion in vivo. In this study, we investigated the role of TCF7L2 expressed in the pancreatic beta cells in glucose homeostasis.

Methods Three independent groups of genetically engineered mice (DN mice) were generated, in which expression of the
\end{abstract}

\footnotetext{
Electronic supplementary material The online version of this article (doi:10.1007/s00125-013-3131-6) contains peer-reviewed but unedited supplementary material, which is available to authorised users.
}

I. Takamoto $\cdot$ N. Kubota $(\bowtie) \cdot K$. Nakaya $\cdot$ K. Kumagai $\cdot$

S. Hashimoto $\cdot$ T. Kubota $\cdot$ M. Inoue $\cdot$ E. Kajiwara $\cdot$ H. Katsuyama

A. Obata $\cdot$ Y. Sakurai $\cdot$ M. Iwamoto $\cdot$ K. Ueki $\cdot$ T. Kadowaki $(\triangle)$

Department of Diabetes and Metabolic Diseases, Graduate School of

Medicine, The University of Tokyo, 7-3-1 Hongo, Bunkyo-ku,

Tokyo 113-8655, Japan

e-mail: nkubota-tky@umin.ac.jp

e-mail: kadowaki-3im@h.u-tokyo.ac.jp

I. Takamoto $\cdot$ N. Kubota $\cdot$ K. Ueki $\cdot$ T. Kadowaki

Translational Systems Biology and Medicine Initiative (TSBMI),

The University of Tokyo, Tokyo, Japan

I. Takamoto $\cdot$ N. Kubota $\cdot$ T. Kubota $\cdot$ M. Inoue

Division of Applied Nutrition, National Institute of Health and

Nutrition, Tokyo, Japan dominant-negative form of $T c f 7 l 2$ was driven under a rat insulin promoter. Phenotypes of both adult and newborn mice were evaluated. The levels of genes and proteins expressed in isolated islets were determined by reverse transcriptionquantitative PCR and western blot analysis, respectively. Results Adult DN mice showed impaired glucose tolerance and decreased insulin secretion in both oral and intraperitoneal glucose tolerance tests. Marked reduction of the beta cell area and whole-pancreas insulin content was observed in both the adult and newborn DN mice. Islets from the DN mice showed decreased gene expressions of Ccnd1, Ccnd2, Irs1, Irs 2, Ins 1, Ins 2 and Mafa, consistent with the deleterious effects of the dominant-negative form of $T c f 7 l 2$ on beta cell proliferation and insulin production.

Conclusions/interpretation TCF7L2 expressed in the pancreatic beta cells plays a crucial role in glucose metabolism through regulation of the beta cell mass.

N. Kubota $\cdot$ T. Kubota

Laboratory for Metabolic Homeostasis, RIKEN Center for

Integrative Medical Sciences, Kanagawa, Japan

K. Kumagai

Laboratory Animal Research Center, Tokyo Medical University,

Tokyo, Japan

T. Kubota

Division of Cardiovascular Medicine, Toho University, Ohashi

Hospital, Tokyo, Japan

T. Kitamura

Metabolic Signal Research Center, Institute for Molecular and

Cellular Regulation, Gunma University, Maebashi, Gunma, Japan 
Keywords Beta cell proliferation · Dominant-negative form . Insulin production · Insulin secretion - TCF7L2 .

$\mathrm{Wnt} / \beta$-catenin signalling

$\begin{array}{ll}\text { Abbreviations } \\ \text { DN mice } & \Delta N-T c f 7 l 2 \text { transgenic mice } \\ \text { Ex-4 } & \text { Exendin-4 } \\ \text { GLP1R } & \text { Glucagon-like peptide 1 receptor } \\ \text { HMG } & \text { High-mobility group } \\ \text { IPGTT } & \begin{array}{l}\text { Intraperitoneal glucose tolerance test } \\ \text { MAFA }\end{array} \\ & \begin{array}{l}\text { v-maf musculoaponeurotic fibrosarcoma } \\ \text { oncogene family, protein A (avian) }\end{array} \\ \text { qPCR } & \text { Quantitative real-time PCR } \\ \text { RIP } & \text { Rat insulin promoter } \\ \text { RT-qPCR } & \text { Reverse transcription-qPCR } \\ \text { SNP } & \text { Single-nucleotide polymorphism } \\ \text { TCF7L2 } & \text { Transcription factor 7-like 2 } \\ \text { TCF/LEF } & \text { T cell factor/lymphoid enhancer-binding factor } \\ \text { Wnt } & \text { Wingless-type MMTV integration site family }\end{array}$

\section{Introduction}

Type 2 diabetes is characterised by peripheral insulin resistance and pancreatic beta cell dysfunction [1,2]. Since 2006, numerous studies, including genome-wide association studies, have generally confirmed a strong association between singlenucleotide polymorphisms (SNPs) in the human gene encoding transcription factor 7-like 2 (TCF7L2) and the risk of onset of type 2 diabetes [3, 4]. These findings have also been confirmed in Asian populations, including the Japanese population [5-7]. The TCF7L2 (formerly known as TCF4) at-risk alleles are associated with specific phenotypes characterised by impaired insulin secretion rather than insulin resistance $[8,9]$. In addition, it has been shown in human studies that these alleles may modify the insulinotropic actions of the incretin hormones $[10,11]$.

TCF7L2 is one of the wingless-type MMTV integration site family (Wnt) $/ \beta$-catenin signalling-associated transcription factors expressed in several tissues, including the pancreas, and vertebrates are known to carry four genes of the TCF/LEF ( $\mathrm{T}$ cell factor/lymphoid enhancer-binding factor) family (TCF7/TCF-1, LEF1, TCF7L1/TCF3 and TCF7L2/TCF4) $[12-14]$. The $\mathrm{Wnt} / \beta$-catenin signalling pathway has been reported to play a distinct role in the development or function of the pancreas $[15,16]$. Deletion of $\beta$-catenin from the pancreatic beta cells of embryonic-stage RIP-Ctnnb1-cKO mice generated by crossing floxed $C t n n b 1$ mice with rat insulin promoter (RIP)-Cre mice resulted in the formation of immature beta cells with reduced pancreatic beta cell area at birth, and glucose intolerance with impaired insulin secretion in the adult stage [17]. Although systemic Tcf7l2 disruption during the embryonic stage by insertion of the hygromycin resistance gene into the exon encoding the DNA-binding high-mobility group (HMG) box caused death in the immediate postnatal period due to the phenotype in the small intestine and liver, the $T c f 7 l 2^{--}$mutant mice showed normal development of the endocrine pancreas and normal beta cell proliferation [18, 19]. Furthermore, deletion of the DNA-binding HMG box after weaning in the pancreatic beta cells of RIP- $E R^{T 2}-T c f 7 l 2-c K O$ mice generated by crossing floxed Tcf 712 mice with RIP-Cre$E R^{T 2}$ mice and injection of tamoxifen did not affect the islet architecture or the beta cell function [19]. Considering the different results on the beta cell development in the neonatal state and insulin secretion in the adult stage obtained between the deletion of $\beta$-catenin and TCF7L2 in the pancreatic beta cells, it is thought that the $\mathrm{Wnt} / \beta$-catenin signalling pathway, including TCF7L2, may play an important role in the development or function of the beta cells and be subject to compensatory mechanisms involving other TCF/LEF family proteins.

The TCF/LEF transcription factors contain a DNA-binding HMG box recognising consensus DNA sequences, as well as an $\mathrm{N}$-terminal $\beta$-catenin-binding domain, and their transcriptional activity is dependent on the co-repressors or co-activators $[12$, 13]. Alternative splicing at the C-terminus of TCF7L2 yields two major isoforms with long and short C-terminal tails (Fig. 1a) $[12,13]$. In addition, a variant of TCF7L2, which lacks the $\mathrm{N}$-terminal $\beta$-catenin-binding domain, namely $\triangle \mathrm{N}$-TCF7L2, has been reported; this variant does not bind $\beta$-catenin and acts as an inhibitor of endogenous $\beta$-catenin and TCF/LEF complexes [20]. In fact, endogenous expression of $\triangle N$-TCF7L2 has been identified in the embryonic forebrain and $\triangle \mathrm{N}-\mathrm{TCF} 7 \mathrm{~L} 2$ has been reported to act in a dominant-negative manner and play a fundamental role in forebrain development [21].

To elucidate the pathophysiological role of TCF7L2 from the embryonic stage in vivo, we adopted RIP-driven $\Delta \mathrm{N}$ TCF7L2 expression and generated genetically engineered mice displaying inhibition of signalling pathways involving other TCF/LEF transcription factors in the pancreatic beta cells. A thorough analysis of these beta cell-specific $\Delta N-T c f 7 l 2$ transgenic mice (DN mice) revealed that the DN mice showed impaired glucose tolerance associated with decreased insulin secretion. In addition, the beta cell area was markedly decreased and the whole-pancreas insulin content was diminished in both the adult and newborn DN mice. Moreover, the islets from the DN mice showed decreased gene expression of $C$ cnd1, Ccnd2, Irs 1, Irs2, Ins1, Ins2 and Mafa. Our results lend support to the hypothesis that the TCF7L2-mediated pathway in pancreatic beta cells plays a crucial role in glucose metabolism through regulation of the beta cell mass during development.

\section{Methods}

Generation of transgenic mice expressing $\triangle N-T C F 7 L 2$ in the pancreatic beta cells (DN mice) A murine full-length, short- 

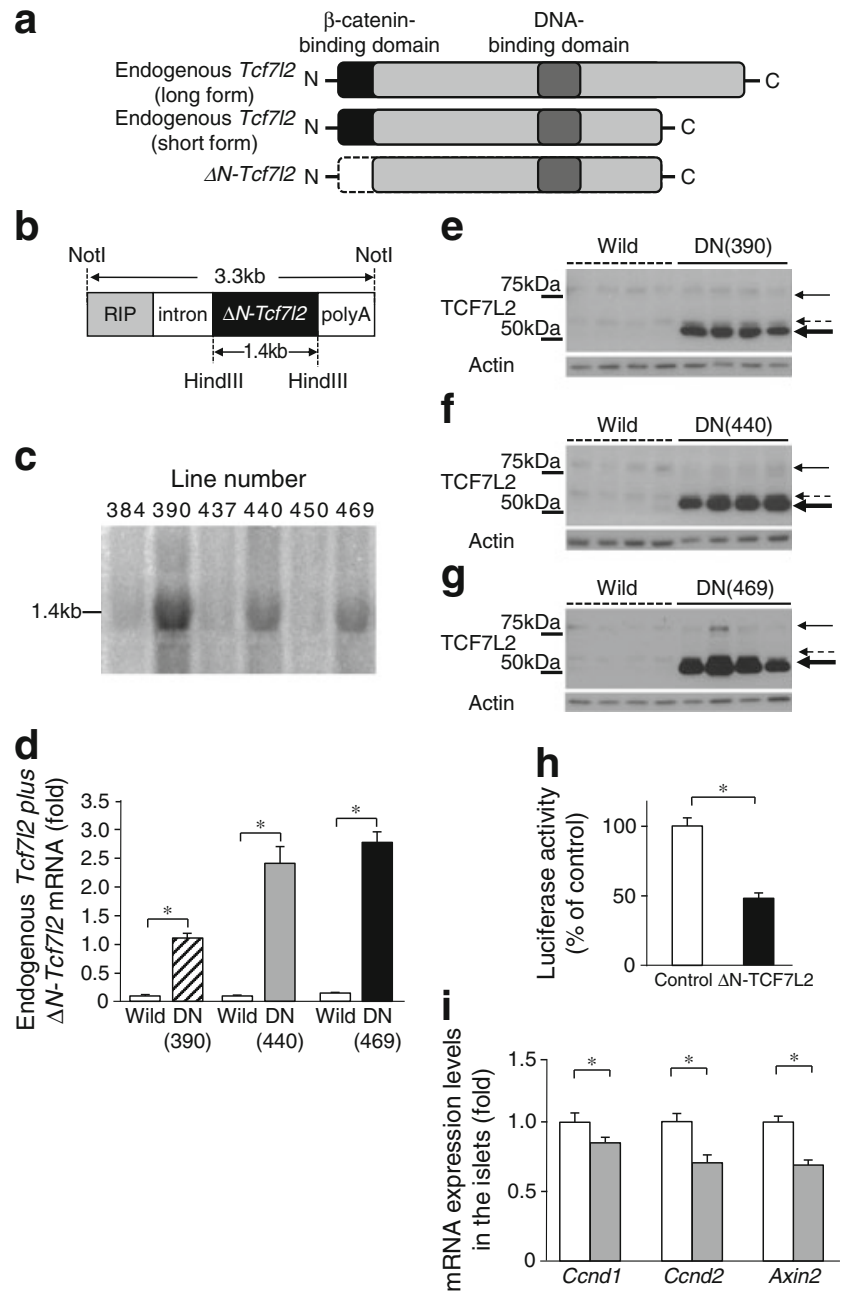

form Tcf7l2 coding sequence cDNA (NM_009333.2) was prepared by cloning the products of RT-PCR from the islet mRNAs of C57BL/6J mice. To obtain mutant truncated cDNA for the $\triangle \mathrm{N}-\mathrm{TCF} 7 \mathrm{~L} 2$ protein, 90 bases were artificially deleted from the $5^{\prime}$ end of the short-form Tcf7l2 by the PCR method $[12,13,22]$. For overexpression in the pancreatic beta cells, the transgene consisted of 757 bases of the rat Ins 2 promoter linked to an intron sequence of rabbit $\beta$-globin, the $5^{\prime}$ end truncated $T c f 7 l 2$ cDNA and a polyadenylation sequence [23]. The construct was inserted into a pBluescript II SK (-) vector (Stratagene, La Jolla, California, USA) and cloned. The purified $3.3 \mathrm{~kb}$ fragment digested by NotI was microinjected into the pronuclei of fertilised BDF2 eggs (CLEA Japan, Tokyo, Japan). The recipient eggs were [C57BL/6J $\times$ DBA/2] F2 hybrids. Transgenic founder or F2 mice were identified by Southern blot analysis of the tail DNAs using a cDNA probe (from exon1 to exon3 of Tcf7l2) and genotyping PCR (see electronic supplementary material [ESM] Methods for further details). The images of the Southern blot analysis were converted to quantitative data (photo-stimulated luminescence intensity) with an image
Fig. 1 Generation of transgenic mice expressing $\triangle \mathrm{N}$-TCF7L2 in the pancreatic beta cells (DN mice). (a) Schematic representation of endogenous full-length $T c f 7 l 2$ (long form and short form) and the $5^{\prime}$ end of truncated $\Delta N-T c f 7 l 2$ cDNA. $\Delta N-T c f 7 l 2$ cDNA lacks 90 bases at the $5^{\prime}$ end corresponding to the $\mathrm{N}$-terminal $\beta$-catenin-binding domain of the full-length, short form Tcf7l2 cDNA. (b) The construct of the transgene. For overexpression in pancreatic beta cells, the transgene consisted of the rat Ins2 gene promoter (RIP) linked to an intron sequence of rabbit $\beta$-globin, $\Delta N$-Tcf7l2 cDNA and a polyadenylation (polyA) sequence. (c) Southern blot analysis of Hind III-digested genomic DNA from six lines of $\mathrm{DN}$ mice. The band at $1.4 \mathrm{~kb}$ corresponded to the transgene and clear bands were observed in all three lines (390, 440 and 469). (d) Expression levels of endogenous $T c f 7 l 2$ plus exogenous $\Delta N-T c f 7 l 2$ mRNA in the pancreatic islets of adult mice were evaluated using littermates of the wild-type (Wild) and DN mice from each line $(n=6)$. Values are the means \pm SEM. ${ }^{*} p<0.05$, DN mice vs wild-type mice. $(\mathbf{e}-\mathbf{g})$ Expression levels of endogenous TCF7L2 and exogenous $\triangle$ N-TCF7L2 protein in the pancreatic islets of adult wild-type and DN mice from each line ( $n=7$ or 8$)$. Antibody against TCF7L2 recognised both endogenous TCF7L2 and exogenous $\triangle$ N-TCF7L2 (thin continuous arrow, endogenous TCF7L2 [long form]; thin dashed arrow, endogenous TCF7L2 [short form]; thick continuous arrow, exogenous $\triangle \mathrm{N}$-TCF7L2). Representative blots are shown for line 390 (e), 440 (f) and 469 (g). The quantified results are shown in ESM Fig. 1c-e. (h) TCF/LEF transcriptional activity in the murine beta cell line MIN6 cells. MIN6 cells were transfected with a control empty vector pcDNA3.1(+) or pcDNA3.1(+)- $\Delta N-T c f 7 l 2(n=8)$. Values are the means \pm SEM. ${ }^{*} p<0.05, \Delta$ N-TCF7L2 vs control. (i) Expression levels of Ccnd1, Ccnd2 and Axin2 mRNA in the pancreatic islets of adult wild-type (white bars) and DN mice (grey bars) from line $440(n=12)$. Data are shown as means \pm SEM. ${ }^{*} p<0.05$, DN mice vs wild-type mice

analyser (BAS 2000, Fuji Film, Tokyo, Japan) [24]. From the six independent lines of transgenic mice obtained, we selected three lines showing obvious expression of $\Delta \mathrm{N}$ TCF7L2 and designated them 390, 440 and 469. The founder and transgenic descendants were backcrossed over five generations into a C57BL/6J background. Male transgenic mice and their wild-type littermates were used for the experiments. The transgenic mice served as heterozygotes.

Animal care C57BL/6J mice were purchased from CLEA Japan. The mice were housed under a $12 \mathrm{~h}$ light-dark cycle and given free access to regular chow (CE-2; CLEA Japan), consisting of $25.6 \%$ (wt/wt) protein, $3.8 \%$ fibre, $6.9 \%$ ash, $50.5 \%$ carbohydrates, $4 \%$ fat and $9.2 \%$ water. The animal care and experimental procedures were approved by the Animal Care Committee of the University of Tokyo.

Western blot analysis Antibodies to TCF7L2, caspase 3 and cleaved caspase 3 were purchased from Cell Signaling Technology (Tokyo, Japan). Anti-actin and anti-MAFA antibodies were purchased from Santa Cruz Biotechnology (Dallas, Texas, USA). The islets were sonicated in ice-cold buffer A (25 mmol/1 Tris-HCl, pH 7.4, $10 \mathrm{mmol} / 1 \mathrm{Na}_{3} \mathrm{VO}_{4}$, $10 \mathrm{mmol} / 1 \mathrm{NaPPi}, 100 \mathrm{mmol} / 1 \mathrm{NaF}, 10 \mathrm{mmol} / \mathrm{l}$ EDTA, $10 \mathrm{mmol} / 1 \mathrm{EGTA}$ and $1 \mathrm{mmol} / 1$ phenylmethylsulfonyl 
fluoride) with an ultrasonic sonicator. Samples were separated by SDS-PAGE, and immunodetection was performed with an ECL kit (Amersham Biosciences, Piscataway, New Jersey, USA) [25]. Protein was prepared from more than 70 islets from each mouse and $15 \mu \mathrm{g}$ samples of the proteins were applied to the gel. Liver samples obtained from C57BL/6J mice administered diethylnitrosamine were used as a positive control for detection of the cleaved caspase 3 protein.

TCF/LEF transcriptional activity The TCF/LEF transcriptional activity in the murine pancreatic beta cell line MIN6 cells [26] co-transfected with pcDNA3.1(+)- $\Delta N-T c f 7 l 2$ or a control empty vector pcDNA3.1(+) was measured using the luciferase reporter gene kit (see ESM Methods for further details).

In vivo glucose homeostasis For the glucose tolerance test, mice were loaded with oral or intraperitoneal glucose $(1.5 \mathrm{~g} / \mathrm{kg}$ body weight) after overnight fasting. Exendin-4 (Sigma, Tokyo, Japan) (24 nmol/kg body weight) was administered $15 \mathrm{~min}$ before the intraperitoneal glucose loading. For the insulin tolerance test, the mice were intraperitoneally challenged with $0.75 \mathrm{U} / \mathrm{kg}$ body weight of human insulin (Novolin R; Novo Nordisk, Tokyo, Japan) after $1 \mathrm{~h}$ of fasting [23] (see ESM Methods for further details).

Reverse transcription-quantitative real-time PCR For reverse transcription-quantitative real-time PCR (RT-qPCR), total RNA was prepared from 40 islets of each mouse. Quantitative real-time PCR (qPCR) was performed using the TaqMan Universal PCR Master Mix or SYBR Green PCR Master Mix (Applied Biosystems, Tokyo, Japan) [27] (See ESM Methods for further details). Commercially available TaqMan Gene Expression Assay IDs and the synthesised primer sequences are listed in ESM Table 1 and ESM Table 2, respectively. The relative expression levels were compared by normalisation to the expression levels of Actb.

Pancreatic islet isolation Isolation of islets from the pancreas of the mice was carried out as described elsewhere [23, 28]. In brief, after clamping the common bile duct at a point close to the duodenal outlet, $2.5 \mathrm{ml}$ of Hanks' Balanced Salt Solution (HBSS) (Sigma) containing $0.6 \mathrm{mg}$ Liberase TL (Roche Diagnostics, Tokyo, Japan) and $25 \mathrm{mmol} / \mathrm{l}$ HEPES were injected into the duct. The swollen pancreas was removed and incubated at $37^{\circ} \mathrm{C}$ for $24 \mathrm{~min}$. The pancreatic tissue was then dispersed by pipetting and washed twice with ice-cold HBSS containing $25 \mathrm{mmol} / \mathrm{l} \mathrm{HEPES}$ and $10 \%$ (wt/vol.) FBS. Thereafter, the islets were manually collected through a stereoscopic microscope and used immediately for the experiments.

Insulin assay of the pancreas For measurement of the insulin content of the whole pancreas, the isolated pancreas was weighed, homogenised in an ethanol/ $\mathrm{HCl}$ buffer and then incubated overnight at $4^{\circ} \mathrm{C}$. At the end of the incubation period, the insulin contained in the buffer was measured with the AlphaLISA insulin kit (PerkinElmer Japan, Yokohama, Japan).

Histological and immunohistochemical analyses of the islets Isolated pancreases were fixed overnight with $4 \%$ paraformaldehyde at $4^{\circ} \mathrm{C}$. Tissues were routinely processed for paraffin embedding and $4 \mu \mathrm{m}$ sections were cut and mounted on silanised slides. The pancreatic sections were stained with anti-insulin antibody (DAKO, Tokyo, Japan) and anti-MAFA antibody [29]. Images of the pancreatic tissues and islet beta cells were viewed on the monitor of a computer through a microscope connected to a camera with a charged-coupled device (Keyence, Osaka, Japan). The areas of the pancreases and the beta cells were traced manually and analysed with WinROOF software ver.5.03 (Mitani, Tokyo, Japan), as previously described [23]. More than 100 islets were analysed per mouse in each group. Bromodeoxyuridine (BrdU) incorporation was analysed with BrdU Labeling and Detection Kit II (Roche Diagnostics) [23] and apoptotic cells were examined using an in-situ Cell Death Detection kit (Roche Diagnostics) (See ESM Methods for further details).

Statistics Results are expressed as means \pm SEM. Differences among groups were examined for statistical significance using the Mann-Whitney $U$ test and Kruskal-Wallis test. A $p$ value of less than 0.05 was considered to indicate statistical significance.

\section{Results}

Generation of transgenic mice expressing $\triangle N$-TCF7L2 in the pancreatic beta cells To inhibit the transcriptional activity of Tcf7l2, 90 bases corresponding to the N-terminal $\beta$-cateninbinding domain were artificially deleted from the $5^{\prime}$ end of the endogenous full-length, short form of Tcf7l2 cDNA (Fig. 1a). For expression in the pancreatic beta cells, the transgene consisted of the rat Ins 2 promoter linked to an intron sequence of rabbit $\beta$-globin, $\Delta N-T c f 7 l 2$ cDNA and a polyadenylation sequence. The purified $3.3 \mathrm{~kb}$ fragment digested by NotI was microinjected into the pronuclei of fertilised BDF2 eggs (Fig. 1b). Transgenic founder mice were identified by Southern blot analysis of the tail DNAs using a cDNA probe, and three independent DN mouse lines, 390, 440 and 469, were selected with a clear band of the exogenous transgene (Fig. 1c). The copy number of each line was estimated to be 15,3 and 3, respectively. To evaluate the expression levels of endogenous $T c f 7 l 2$ plus exogenous $\Delta N-T c f 7 l 2$ mRNA, the primer probe set was designed based on the sequence between 
exon 5 and exon 6 (ESM Fig. 1a). In the isolated islets of the DN mice, a more than tenfold increase in the exogenous expression level of $\Delta N-T c f 7 l 2$ was found as compared with the endogenous expression level of Tcf7l2 (Fig. 1d). Similar results were confirmed by western blot analysis and a slight increase in endogenous TCF7L2 was observed in the islets of the DN mice (Fig. 1e-g, ESM Fig. 1b-e). No exogenous expression of $\Delta N-T c f 7 l 2$ was detected in any other tissues, including the hypothalamus (data not shown). Induction of exogenous $\triangle \mathrm{N}$-TCF7L2 suppressed the TCF/LEF transcriptional activity in the murine beta cell line MIN6 cells (Fig. 1h). In addition, the expression levels of $C c n d 1, C c n d 2$ and Axin2, which are known direct target genes of TCF7L2 [30, 31 , were significantly decreased in the islets of the DN mice from line 440 as compared with the corresponding expression levels in the wild-type mice (Fig. 1i).
Adult DN mice developed impaired glucose tolerance associated with decreased insulin secretion as assessed by the OGTT There were no significant differences in body weight between 10-week-old $\mathrm{DN}$ mice and their wild-type littermates (Fig. 2a-c). The blood glucose levels in the ad libitum condition were significantly higher in the DN mice than those in the wild-type mice (Fig. 2d-f). The glucose-lowering effect of insulin was similar between the DN mice and wild-type mice from all three lines (Fig. 2g-i, ESM Fig. 2a-c). In all mouse lines, the OGTT showed that the blood glucose levels after glucose loading were significantly elevated in the DN mice (Fig. 2j-1), along with lower insulin secretion (Fig. $2 \mathrm{~m}-\mathrm{o}$ ). These results indicate that the adult DN mice developed impaired glucose tolerance associated with decreased insulin secretion.
Fig. 2 Adult DN mice showed impaired glucose tolerance associated with decreased insulin secretion as assessed by the OGTT. Body weight $(\mathbf{a}-\mathbf{c})$ and blood glucose levels $(\mathbf{d}-\mathbf{f})$ in the ad libitum condition (ad lib) of 10-week-old wild-type (Wild) and DN mice from each line $(n=12)$. Blood glucose levels (ratio baseline) during the insulin tolerance test (ITT) $(\mathbf{g}-\mathbf{i})$ in 10-week-old wild-type (white diamonds) and DN mice (black squares) from each line $(n=12)$. Raw data on the blood glucose levels are shown in ESM

Fig. 2a-c. Blood glucose $(\mathbf{j}-\mathbf{l})$ and serum insulin levels $(\mathbf{m}-\mathbf{0})$ during the OGTT in 11-week-old wild-type (white diamonds) and DN mice (black squares) from each line $(n=8-12)$. Results for line 390 (a, d, g, j, m), 440 $(\mathbf{b}, \mathbf{e}, \mathbf{h}, \mathbf{k}, \mathbf{n})$ and 469 $(\mathbf{c}, \mathbf{f}, \mathbf{i}, \mathbf{l}, \mathbf{o})$ are shown as means \pm SEM. ${ }^{*} p<0.05$, DN mice vs wild-type mice a

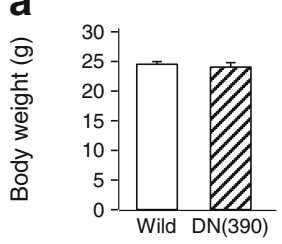

d

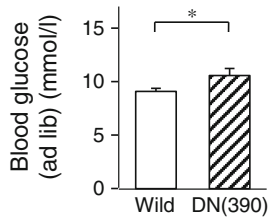

g
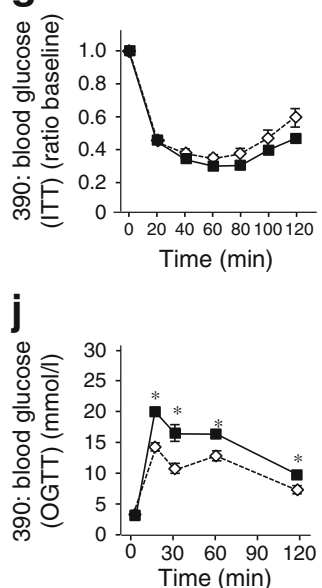

m

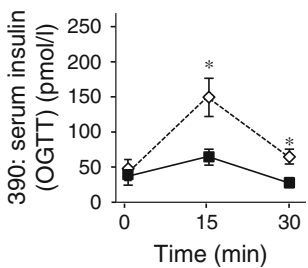

b

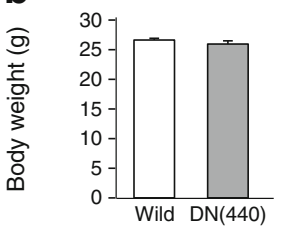

e

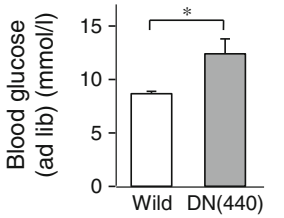

h
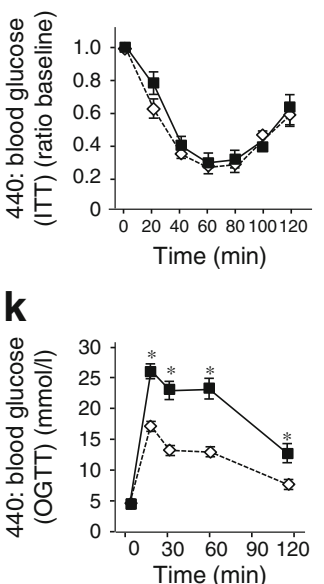

n

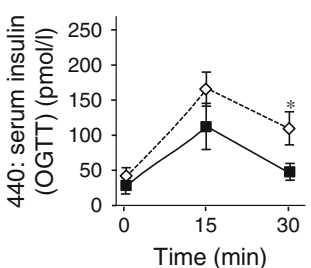

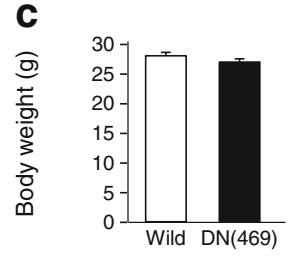

f

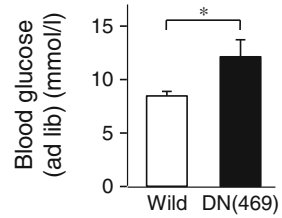

i

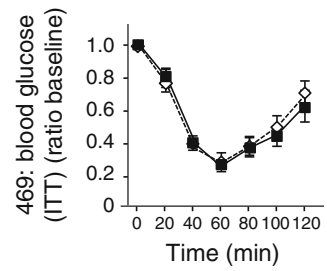

I

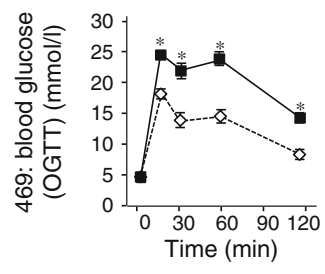

0

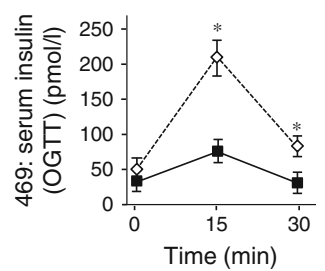


The incretin effect of exogenous glucagon-like peptide 1 receptor agonist administration observed in DN mice was similar to that in wild-type mice To evaluate the incretin effect in DN mice, an intraperitoneal glucose tolerance test (IPGTT) was performed with and without administration of the exogenous glucagon-like peptide 1 receptor (GLP1R) agonist exendin-4 (Ex-4). In all three lines, the blood glucose levels after glucose loading with normal saline were significantly elevated in the DN mice compared with the wild-type mice (Fig. 3a-c), as measured during the OGTT (Fig. 2j-1). On the other hand, after administration of Ex-4, the blood glucose levels decreased to similar degrees in the DN mice and wildtype mice (Fig. 3d-f). In addition, the serum insulin levels were significantly elevated in both the wild-type and DN mice following Ex-4 administration (Fig. 3g-i). There was no significant difference in the plasma level of total GLP-1 between the wild-type and DN mice (data not shown). These results suggest that the short-term incretin effect was preserved in the DN mice.

Beta cell area and whole-pancreas insulin content were diminished in the adult DN mice To investigate the mechanism of impairment of insulin secretion in the DN mice, the pancreatic insulin content and beta cell area were measured. The whole-pancreas insulin content was significantly diminished in the adult DN mice (Fig. $4 \mathrm{a}-\mathrm{c}$ ). The beta cell area ratio per whole pancreas and area of beta cells in each islet were markedly decreased (Fig. 4d-f), with a tendency towards a low BrdU incorporation in the DN mice (Fig. 4g). On the other hand, no significant differences in the frequency of apoptosis of the beta cells were observed among these mice (Fig. 4h), with apoptotic cells scarcely detectable in histological sections. Consistent with these findings, the expression levels of Casp3 mRNA and caspase 3 protein in the islets were not significantly different between the wild-type and DN mice, and cleaved caspase 3 protein was scarcely detectable in the islets of either the wild-type mice or the DN mice (Fig. 4i, j).

Islets from the DN mice showed decreased gene expression of Ins1, Ins2, Irs1, Irs2 and Mafa We performed RT-qPCR analysis of the isolated islets. In accordance with the diminished pancreatic insulin content, the expression levels of Ins 1 and Ins2, along with those of Neurod1 and Mafa, were also significantly decreased in the DN mice (Fig. 5a). The expression levels of Irs 1 and Irs2, as well as those of Ccnd1 and Ccnd2, were also significantly decreased in these mice (Figs 5a and 1i). The expression level of Glp1r was also reduced in the islets of the DN mice. In contrast, the mRNA expression levels of molecules associated with the secretory machinery did not differ significantly between the wild-type and DN mice (Fig. 5b); this was consistent with previous results obtained from pancreas-specific $T c f 7 l 2$-null mice [31]. MAFA (v-maf musculoaponeurotic fibrosarcoma
Fig. 3 The incretin effect of exogenous GLP1R agonist administration observed in the DN mice was similar to that in the wild-type mice. Blood glucose levels $(\mathbf{a}-\mathbf{c})$, AUC of blood glucose levels (d-f) and serum insulin levels $(\mathbf{g}-\mathbf{i})$ during the IPGTT with Ex-4 or normal saline (NS) in 11-week-old wild-type (Wild) and DN mice from each line $(n=4-6)$. Dotted line with white square, wild-type mice with NS; dotted line with white circle, wild-type mice with Ex-4; continuous line with black square, DN mice with NS; continuous line with black circle, DN mice with Ex-4. Results for line 390 (a, d, g), 440 (b, e, h) and 469 $(\mathbf{c}, \mathbf{f}, \mathbf{i})$ are shown as means \pm SEM. ${ }^{*} p<0.05$, DN mice given $\mathrm{NS}$ vs wild-type mice given NS; ${ }^{\dagger} p<0.05$, DN mice given Ex-4 vs DN mice given NS
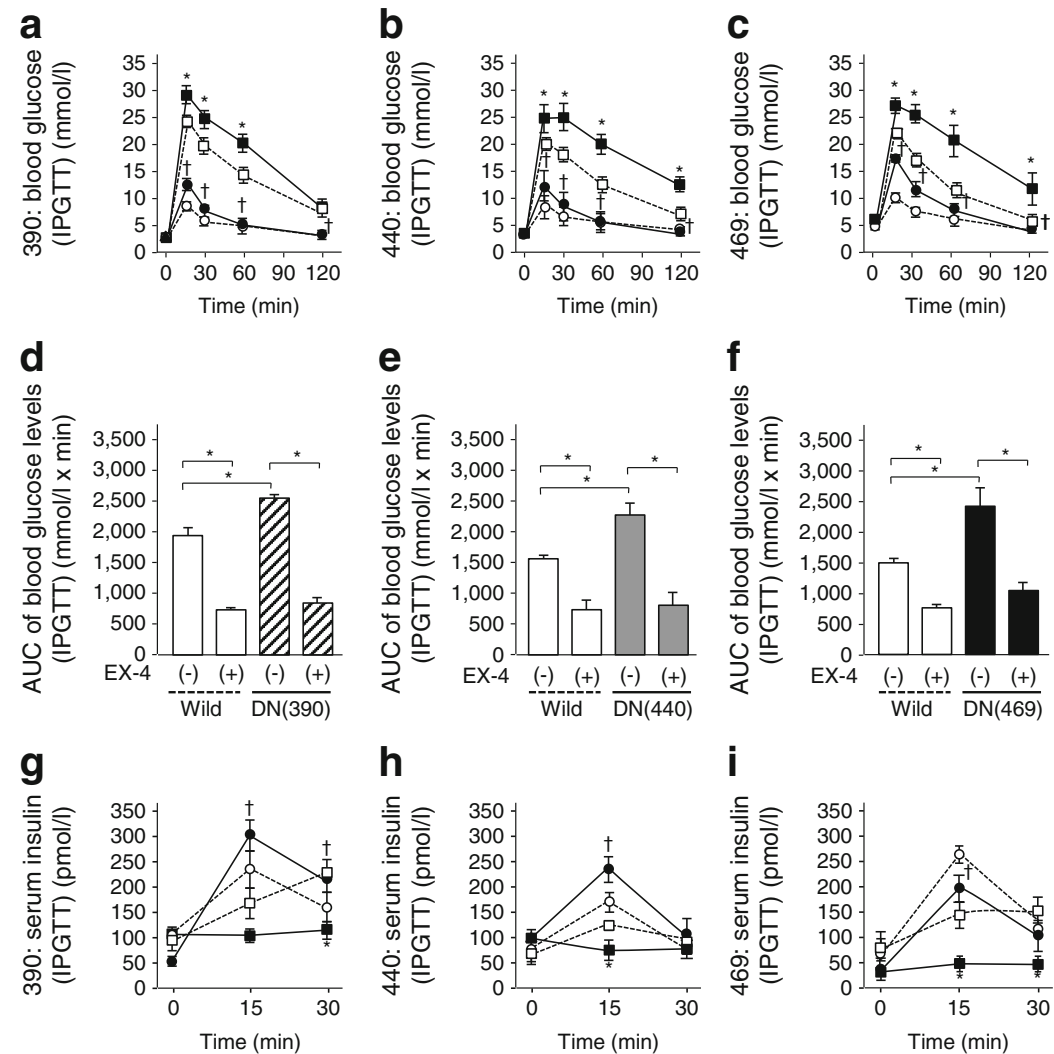

h

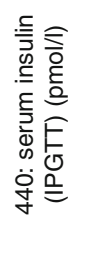

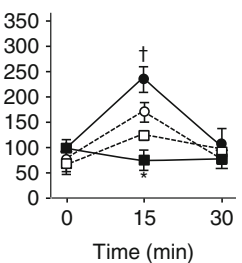

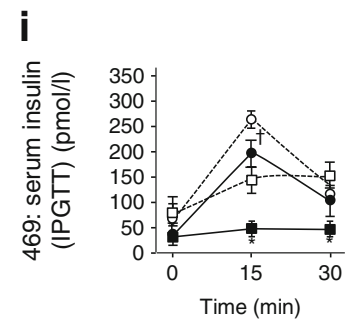


Fig. 4 Beta cell area and wholepancreas insulin content were diminished in adult DN mice. Whole-pancreas insulin content (a-c) of 12-week-old wild-type (Wild) and DN mice from each line $(n=12)$. Results for line 390 (a), 440 (b) and 469 (c). (d) Immunohistochemical analysis of the pancreas for insulin (red) and $\mathrm{BrdU}$ (green) incorporation in 12-week-old mice. Scale bar, $100 \mu \mathrm{m}$. Beta cell area ratio per whole pancreas (e), area of the beta cells in each islet (f), number of BrdU-positive cells (g) and number of apoptotic cells $(\mathbf{h})$ per beta cell area of $10,000 \mu \mathrm{m}^{2}$ in 12-week-old mice $(n=8-10)$. (i) Expression levels of Casp 3 mRNA in the islets of the wildtype and DN mice from line 440 $(n=12)$. (j) Expression levels of caspase 3 and cleaved caspase 3 protein in the islets of the wildtype and DN mice from line 440 $(n=3)$. Cleaved caspase 3 protein was hardly detected in the islets of either the wild-type or the DN mice. Liver sample from C57BL/6J mice administered diethylnitrosamine was used as positive control. Data are shown as means \pm SEM. $* p<0.05, \mathrm{DN}$ mice vs wild-type mice
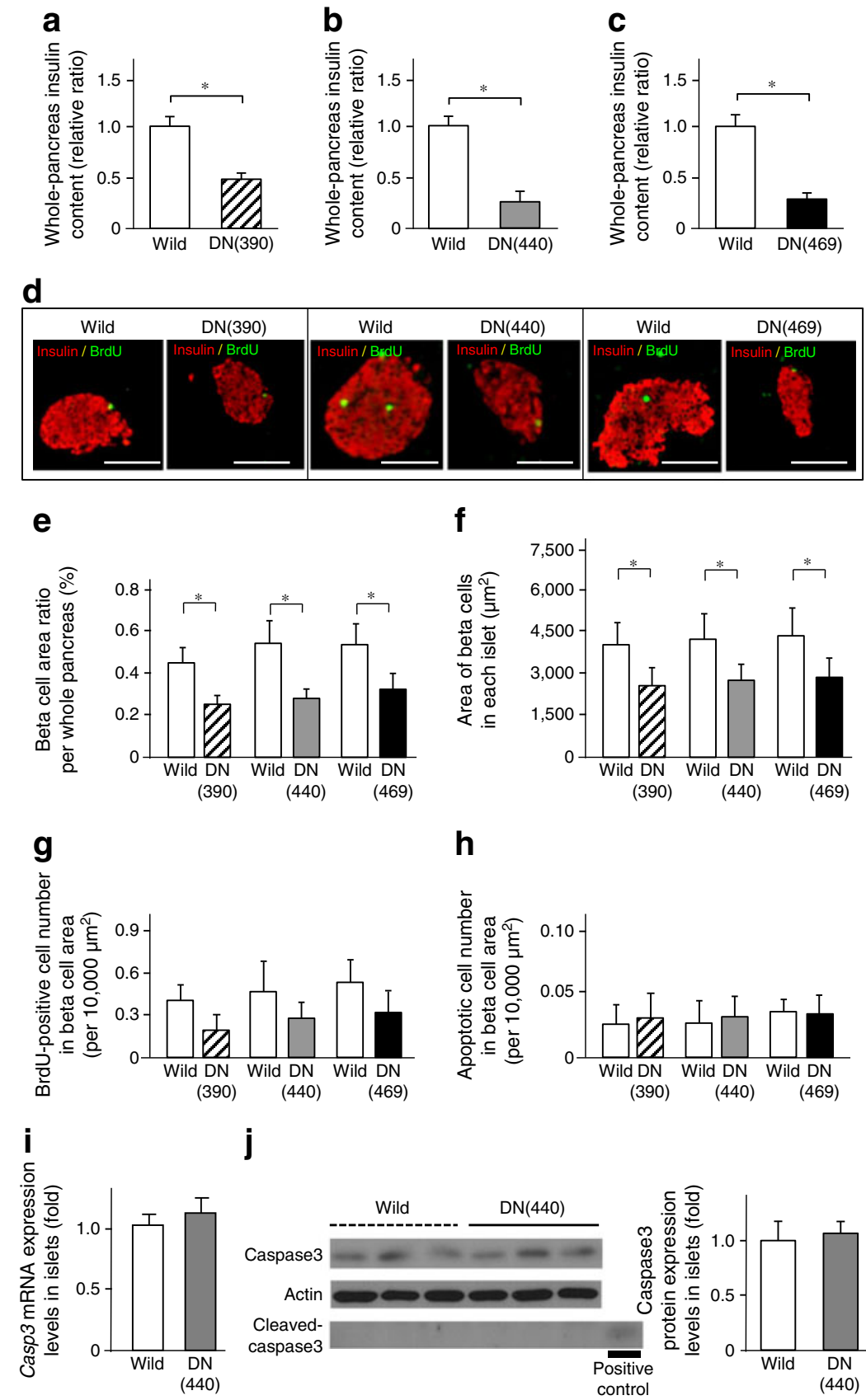

j
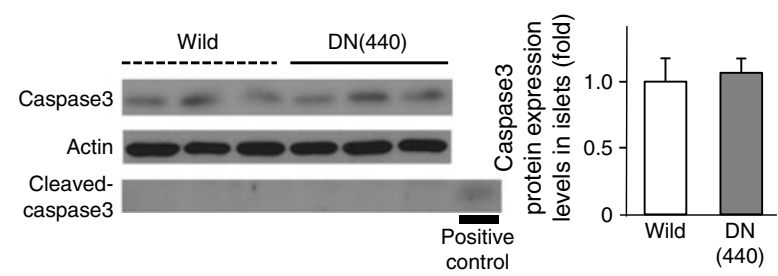

oncogene family, protein A [avian]) is well known as a key transcription factor for beta cell maturation and insulin transcription $[32,33]$. Indeed, reduced stainability and protein expression levels of MAFA were observed in the islets of the DN mice (Fig. 5c, d), which coincided with the impaired expression of Ins 1 and Ins 2 .

DN mice developed impaired glucose tolerance associated with decreased insulin secretion at the time of weaning To investigate whether the phenotypes of adult DN mice were observed at younger ages, 4-week-old mice were evaluated. While 4-week-old DN mice and their wild-type littermates exhibited no significant differences in body weight (Fig. 6a-c), the blood glucose levels were significantly elevated in the DN mice from lines 440 and 469 (Fig. 6d-f), in which the expression levels of exogenous $\triangle$ N-TCF7L2 were relatively high (Fig. 1d-g). In all three lines, the blood glucose levels after oral glucose loading were significantly elevated in the DN mice, with lower insulin secretion during the OGTT (Fig. $6 \mathrm{~g}-\mathrm{i}, \mathrm{j}-1$ ). The whole-pancreas insulin content was significantly diminished in the DN mice (Fig. 6m-o).

The beta cell area and whole-pancreas insulin content were diminished in newborn DN mice While the body weights 

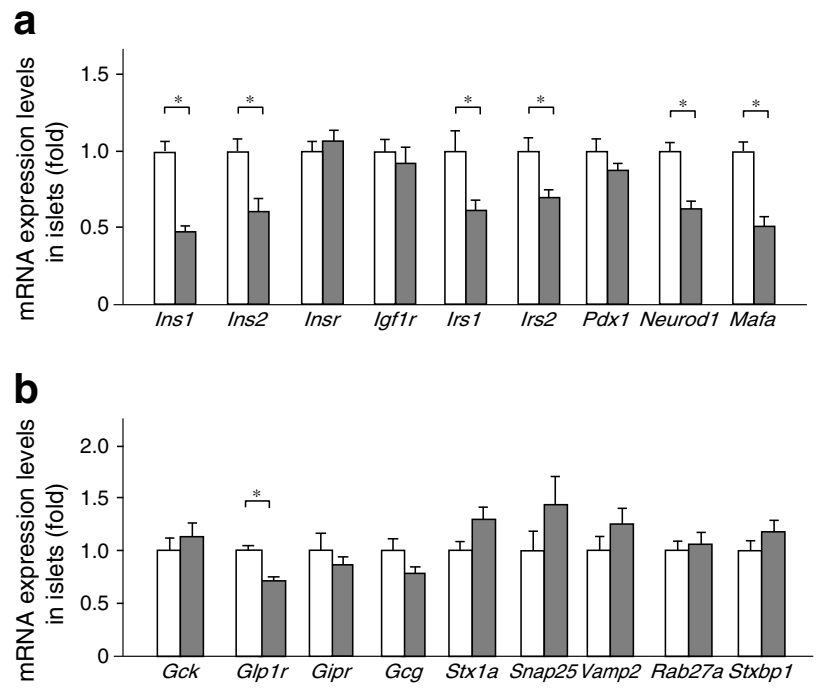

C
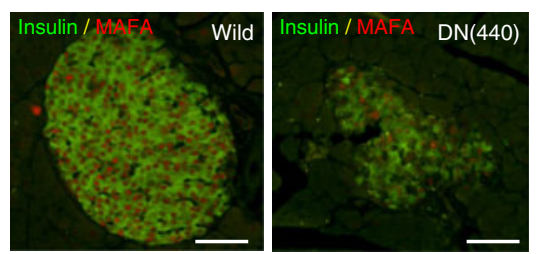

d
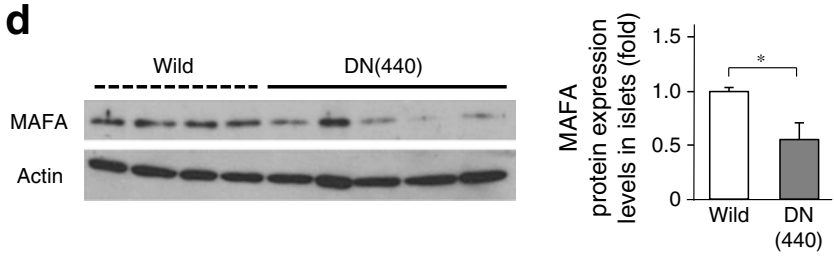

Fig. 5 Islets from DN mice showed decreased gene expression of Ins 1 , Ins 2, Irs 1 , Irs 2 and Mafa . (a, b) RT-qPCR results in isolated islets of 12week-old wild-type (white bars) and DN (grey bars) mice from line 440 $(n=12)$. The gene expression levels were normalised to those of Actb. (c) Immunohistochemical analysis of the pancreas for insulin (green) and MAFA (red) in adult wild-type (Wild) and DN mice from line 440. Scale bar, $20 \mu \mathrm{m}$. (d) Expression levels of MAFA protein in the pancreatic islets of adult mice. Protein levels were evaluated using wild-type $(n=4)$ and DN $(n=5)$ mice from line 440 . Data are shown as means \pm SEM. ${ }^{*} p<0.05$, DN mice vs wild-type mice

were similar (Fig. 7a-c), blood glucose levels of the newborn DN mice from lines 440 and 469 were significantly elevated (Fig. 7d-f) compared with wild-type littermates. The wholepancreas insulin content of newborn mice was diminished in all the three lines of DN mice (Fig. $7 \mathrm{~g}-\mathrm{i}$ ). Consistent with this finding, the beta cell area was significantly decreased in the newborn DN mice (Fig. 7j, k), compared with their wild-type littermates, and this was also associated with significantly reduced beta cell proliferation (Fig. 71). These findings suggest that the TCF7L2-mediated pathway may exert an effect on the development of the beta cells during the embryonic stage.

\section{Discussion}

TCF7L2 has been identified as a strong type 2 diabetes susceptibility gene and TCF7L2 at-risk alleles have been shown to be associated with clinical phenotypes of impaired insulin secretion $[3-5,8,9]$. To elucidate the pathophysiological role of TCF7L2 from the embryonic stage in vivo, DN mice with impaired function of TCF7L2 in the pancreatic beta cells were generated. In a thorough analysis of three independent lines of DN mice, we observed that adult DN mice developed impaired glucose tolerance associated with decreased insulin secretion, as assessed by both OGTT and IPGTT. The beta cell area was markedly decreased and the total insulin content of the whole pancreas was also diminished in the adult DN mice. Moreover, the reduction of the beta cell area and pancreatic insulin content was even observed in the newborn DN mice. Consistent with these findings, islets from the DN mice showed decreased gene expressions of Ccnd1, Ccnd2, Irs1, Irs2, Ins 1, Ins2 and Mafa, the latter of which is well known to encode for a key transcription factor of beta cell maturation and insulin transcription [32, 33]. These data suggest that the TCF7L2-mediated pathway in the pancreatic beta cells contributes to glucose homeostasis through regulation of the beta cell mass during development.

The $\mathrm{Wnt} / \beta$-catenin signalling pathway is well known to play a critical role during embryonic development, stem cell differentiation and tumorigenesis $[4,12-14]$. In the pancreatic islets, many splice variants of the TCF $2 L 2$ gene are expressed and known to have distinct physiological and pathophysiological effects on the beta cells [34-36]. In addition, the diversity of vertebrate TCF/LEF isoforms plays an important role in mediating the various functions of $\mathrm{Wnt} / \beta$-catenin signalling [37]. In fact, expression of Tcf7ll and Tcf7, as well as of $T c f 7 l 2$, has been reported in the pancreas [38]. Genetically engineered animal models of $T c f 7 l 2$, generated using different targeting strategies, disrupted exons and $\mathrm{Cre}$ mouse strains have shown a variety of phenotypes $[18,19,31$, 39-43]. In this study, we adopted $\triangle$ N-TCF7L2, which theoretically functions as a dominant-negative molecule to inhibit functional TCF7L2 isoforms and other TCF/LEF family proteins at the TCF7L2 binding sites [42], and confirmed that induction of exogenous $\triangle \mathrm{N}-\mathrm{TCF} 7 \mathrm{~L} 2$ suppressed the TCF/ LEF transcriptional activity in a pancreatic beta cell line (Fig. 1h). In addition, the expression levels of established target genes of TCF7L2 were significantly decreased in the pancreatic islets of the DN mice (Fig. 1i). Dysregulation of glucose homeostasis and the beta cell area was evident from birth through to the adult stage in the DN mice, since the function of the TCF7L2-mediated pathway may be impaired from the embryonic stage without any compensatory mechanisms. Expression of Tcf7ll was observed in the pancreatic islets as well as other tissues (ESM Fig. 3). Although the precise role of TCF7L1 in glucose homeostasis and beta cell 
Fig. 6 DN mice at weaning age developed impaired glucose tolerance associated with decreased insulin secretion as assessed by the OGTT. Body weight $(\mathbf{a}-\mathbf{c})$ and blood glucose levels $(\mathbf{d}-\mathbf{f})$ in the ad libitum condition (ad lib) of 4-week-old wild-type (Wild) and DN mice from each line $(n=8)$. Blood glucose $(\mathbf{g}-\mathbf{i})$ and serum insulin levels $(\mathbf{j}-\mathbf{l})$ during the OGTT using 4-week-old wild-type (white diamonds) and $\mathrm{DN}$ mice (black squares) from each line $(n=8)$. $(\mathbf{m}-\mathbf{o})$ Whole-pancreas insulin content of 4-week-old wild-type and DN mice from each line $(n=8-12)$. Results for line $390(\mathbf{a}, \mathbf{d}, \mathbf{g}, \mathbf{j}, \mathbf{m}), 440(\mathbf{b}, \mathbf{e}, \mathbf{h}$, $\mathbf{k}, \mathbf{n})$ and $469(\mathbf{c}, \mathbf{f}, \mathbf{i}, \mathbf{l}, \mathbf{o})$ are shown as means \pm SEM. ${ }^{*} p<0.05, \mathrm{DN}$ mice vs wild-type mice
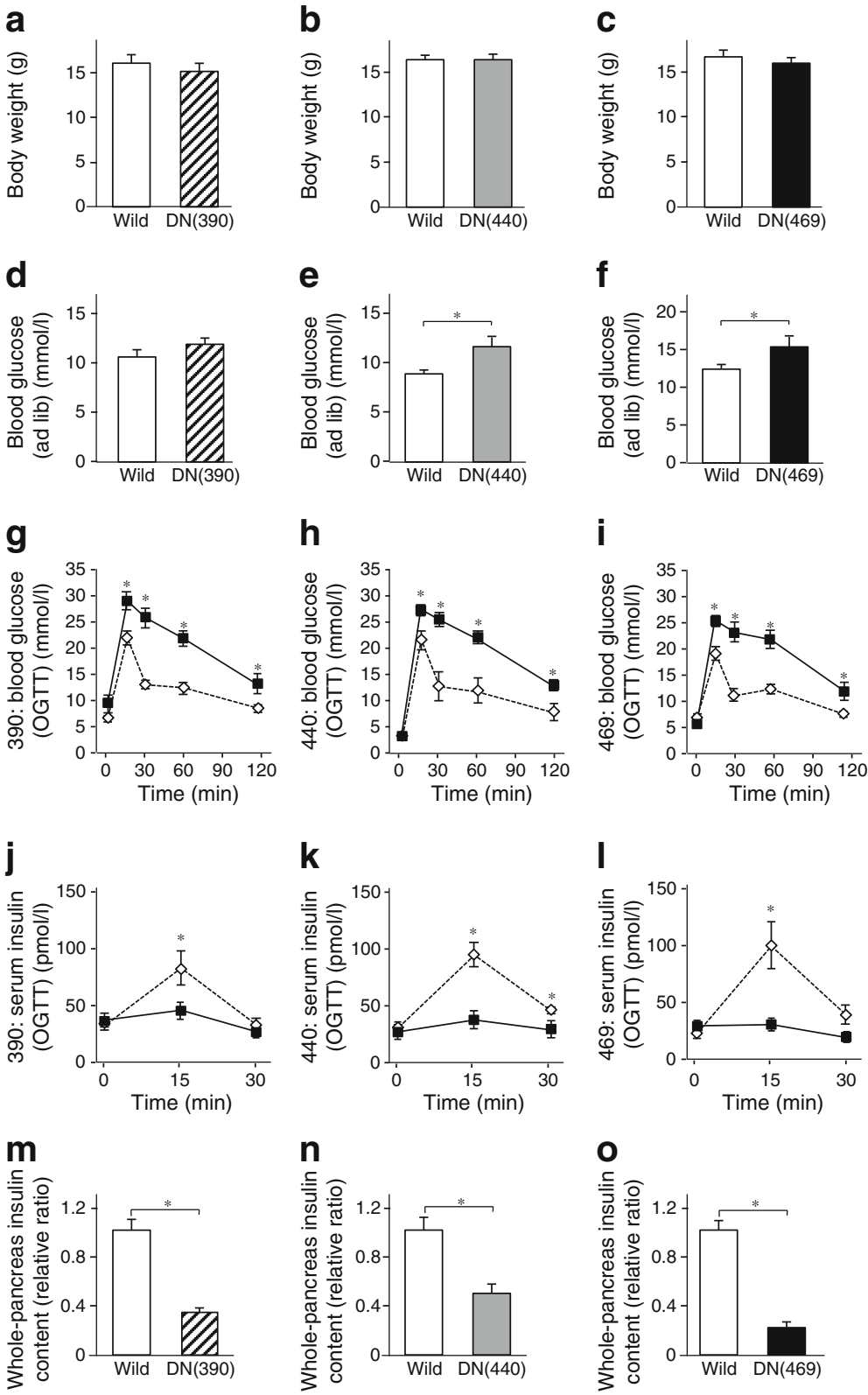

development is mostly unknown because of the embryonic lethality of systemic Tcf7ll knockout mice [44], comparisons of the phenotypes of DN mice and other mice with genetically modified Tcf7l2 suggest that TCF7L1 may compensate for the lack of TCF7L2 actions on the beta cells. Further investigation is warranted to determine whether TCF7L1 might regulate the development of the pancreatic beta cells in coordination with TCF7L2.

Islets from the $\mathrm{DN}$ mice showed decreased gene expressions of $C c n d 1, C c n d 2, \operatorname{Irs} 1$ and Irs2, which may be the cause of the reduction in the beta cell area. Consistent with this notion, previous experiments using the pancreatic beta cell line INS- 1 cells demonstrated that TCF7L2 protein bound to the promoter region of $C c n d 1$ and exogenous $\triangle \mathrm{N}-\mathrm{TCF} 7 \mathrm{~L} 2$ indeed inhibited the proliferation of INS-1 cells by $50 \%$ as compared with control cells expressing an empty vector [45]. We and others have provided genetic evidence of the role of insulin-signalling pathways in the beta cells for regulating the beta cell mass in vivo [23, 27, 46, 47]. Although the expression level of Insr was unaltered, levels of Irs 1 and Irs 2 were diminished in the islets of the DN mice. In addition, reduced gene expressions of Mafa and Neurod1, which encode important transcription factors of beta cell maturation and insulin transcription [32], may contribute to the observed phenotypes of the DN mice. Further study is needed to clarify the possibility of direct regulation of $\operatorname{Irs} 1, \operatorname{Irs} 2, \mathrm{Mafa}$ and Neurod1 by TCF7L2 in beta cells. 
Fig. 7 Beta cell area and wholepancreas insulin content were diminished in newborn $\mathrm{DN}$ mice. Body weight $(\mathbf{a}-\mathbf{c})$ and blood glucose levels $(\mathbf{d}-\mathbf{f})$ of newborn wild-type (Wild) and DN mice from each line $(n=10)$. Wholepancreas insulin content $(\mathbf{g}-\mathbf{i})$ of the newborn wild-type and DN mice from each line $(n=8-12)$. Results are shown for lines 390 (a, d, g), 440 $(\mathbf{b}, \mathbf{e}, \mathbf{h})$ and $469(\mathbf{c}, \mathbf{f}, \mathbf{i}) .(\mathbf{j})$ Immunohistochemical analysis of the pancreas for insulin in newborn mice. Scale bar, $300 \mu \mathrm{m}$. Beta cell area ratio per whole pancreas (k) and number of BrdU-positive cells (l) per beta cell area of $10,000 \mu \mathrm{m}^{2}$ in the newborn mice $(n=12-15)$. Data are shown as means \pm SEM. ${ }^{*} p<0.05, \mathrm{DN}$ mice vs wild-type mice
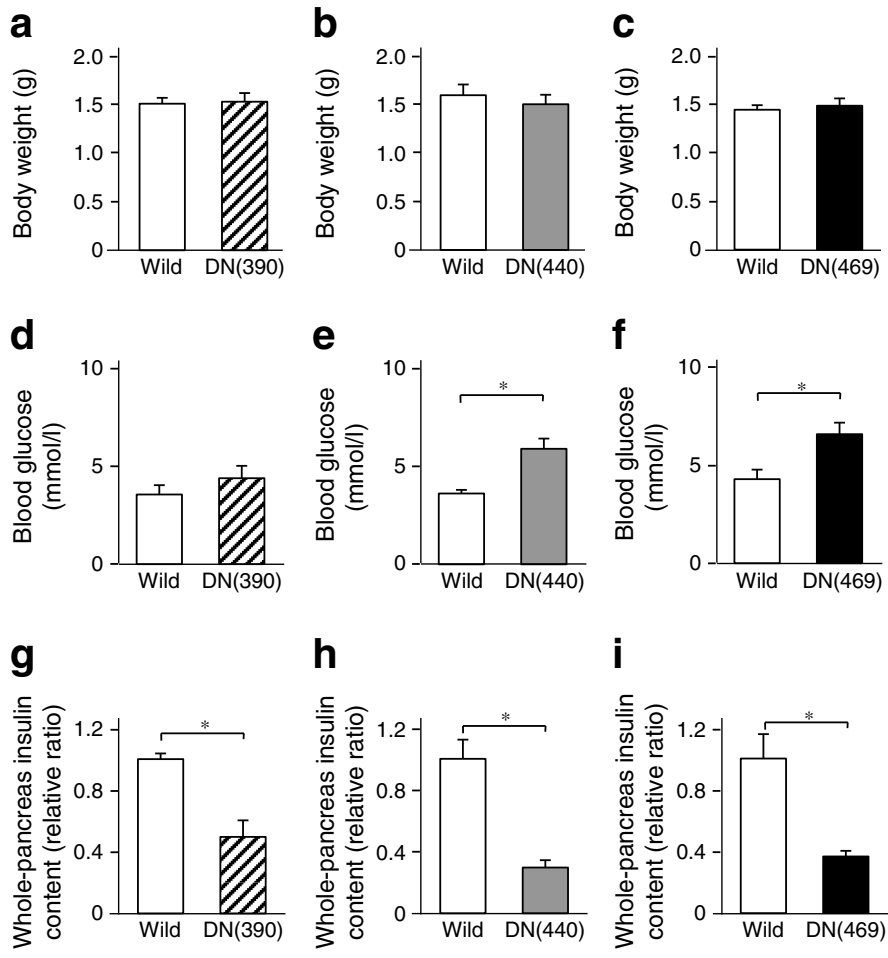

h
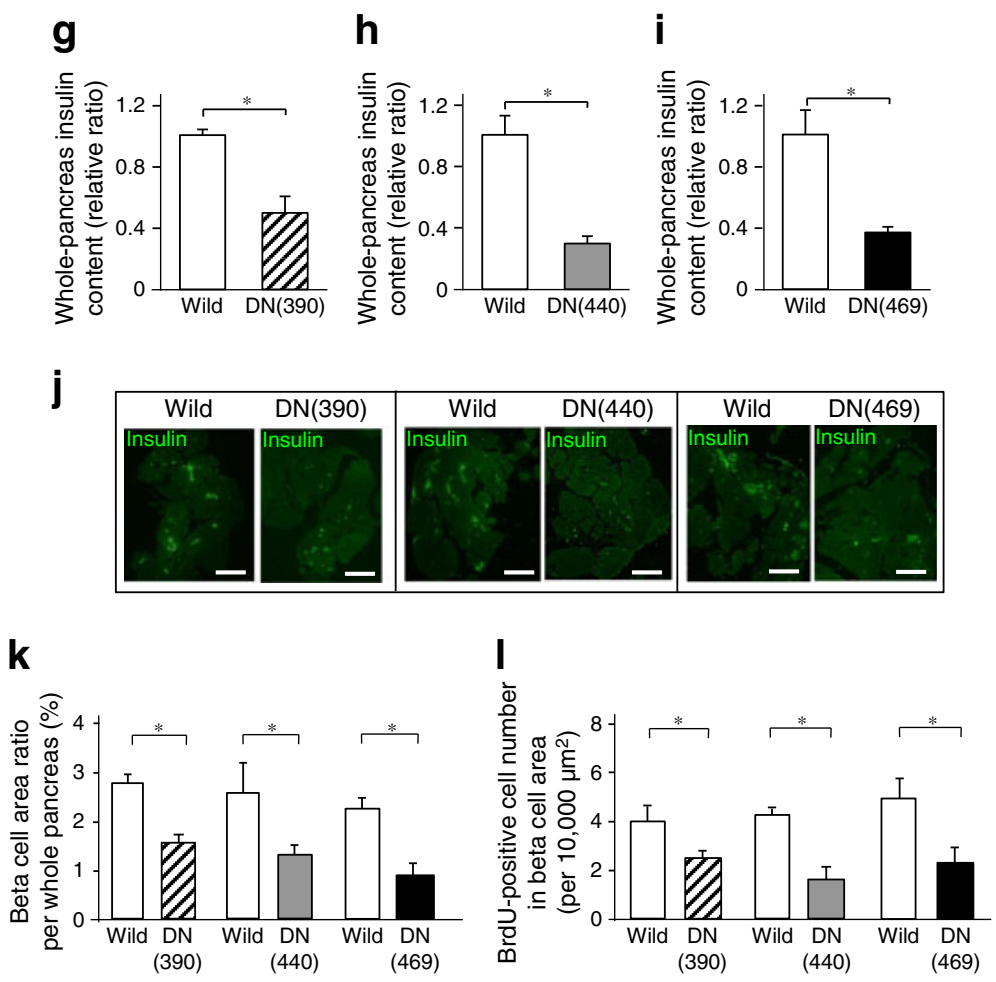

In a study in humans, a positive correlation has been observed between the mRNA levels of TCF7L2 and the insulin gene, although the expression of TCF7L2 mRNA was correlated inversely with the glucose-stimulated insulin secretion rate after normalisation for the total insulin content [10]. Consistent with these data, in the islets of the DN mice, the expression levels of Ins 1 and Ins 2 were reduced, whereas the expression levels of molecules associated with the secretory machinery were not decreased. The possibility that the TCF7L2 at-risk alleles may modify the insulinotropic actions of incretin hormones in humans is still under debate [10, 11, 48]. In DN mice, a single administration of Ex-4 improved the glucose tolerance, with elevated serum insulin levels. The short-term incretin effect was preserved in the DN mice, probably due to the mild reduction of Glplr and unaltered secretory machinery in the islets.

It has been reported that rs7903146, a TCF7L2 intronic variant strongly associated with type 2 diabetes, is located in islet-selective open chromatin, consistent with the observation of increased TCF7L2 mRNA expression in the islets isolated from type 2 diabetic patients [49]. However, it has been demonstrated that the protein levels of TCF7L2 are depressed in the islets of patients with type 2 diabetes and animal models of diabetes, while TCF7L2 mRNA levels are increased [50]. In addition to the discrepancy between the increased mRNA and decreased protein expression of $T C F 7 L 2$, the existence of various TCF7L2 splice variants should be considered to interpret the role of TCF7L2 in the beta cells $[34,36]$. Indeed, 
function-specific transcripts of TCF7L2, which exerted distinct effects on beta cell function and survival, were detected in human beta cells, and increased levels of deleterious TCF7L2 splice variants may explain the impaired insulin secretion in type 2 diabetes [35]. Further analysis of pancreatic beta cells from individuals with at-risk alleles of TCF7L2 or from patients with type 2 diabetes will be required to examine the changes in both the mRNA and protein expression patterns of TCF7L2, including other TCF/LEF family genes and endogenous dominant-negative forms.

In this study, we demonstrated that the expression of the dominant-negative form of TCF7L2 from the embryonic stage in the pancreatic beta cells was associated with a reduction in beta cell area and pancreatic insulin content in the newborn mice, leading to impaired glucose tolerance with decreased insulin secretion in the adult stage. Thus, our findings suggest that TCF7L2 in the pancreatic beta cells plays a crucial role in glucose metabolism through regulation of the beta cell mass during development.

Acknowledgements We thank E. Hirata, A. Nagano, Y. Okonogi, M. Henmi and N. Ishikawa of the University of Tokyo for their excellent technical assistance and help with the animal care.

Funding This work was supported by a grant for TSBMI from the Ministry of Education, Culture, Sports, Science and Technology of Japan, a Grant-in-aid for Scientific Research in Priority Areas (A) (16209030), (A) (18209033) and (S) (20229008) from the Ministry of Education, Culture, Sports, Science and Technology of Japan (to TKa), and a Grant-in-aid for Young Scientists (B) (23791017) from the Japan Society for the Promotion of Science (to IT).

Duality of interest The authors declare that there is no duality of interest associated with this manuscript.

Contribution statement IT, NK, KU and TKa were the main contributors in terms of study conception and design, acquisition and interpretation of data and writing the manuscript. $\mathrm{KN}, \mathrm{KK}$ and $\mathrm{SH}$ contributed substantially to conceptual design, acquisition of data and revising the manuscript. TKu, MIn, HK, AO and YS made substantial contributions to analysis and interpretation of data, discussion of the results and drafting the manuscript. EK and MIw contributed substantially to conceptual design, acquisition of data for transcriptional activities and the critical revision of the manuscript for important intellectual content. TKi made substantial contributions to conceptual design, acquisition of data for immunohistochemical analyses and critical revision of the manuscript for important intellectual content. TKa is the guarantor of this work and as such had full access to all the data in the study and takes responsibility for the integrity of the data and accuracy of the data analysis. All authors gave final approval of the version to be published.

\section{References}

1. Kadowaki T, Miyake Y, Hagura R et al (1984) Risk factors for worsening to diabetes in subjects with impaired glucose tolerance. Diabetologia 26:44-49

2. Kadowaki T (2000) Insights into insulin resistance and type 2 diabetes from knockout mouse models. J Clin Invest 106:459-465
3. Grant SF, Thorleifsson G, Reynisdottir I et al (2006) Variant of transcription factor 7-like 2 (TCF7L2) gene confers risk of type 2 diabetes. Nat Genet 38:320-323

4. Liu Z, Habener JF (2010) Wnt signaling in pancreatic islets. Adv Exp Med Biol 654:391-419

5. Horikoshi M, Hara K, Ito C, Nagai R, Froguel P, Kadowaki T (2007) A genetic variation of the transcription factor 7-like 2 gene is associated with risk of type 2 diabetes in the Japanese population. Diabetologia 50:747-751

6. Miyake K, Horikawa Y, Hara K et al (2008) Association of TCF7L2 polymorphisms with susceptibility to type 2 diabetes in 4,087 Japanese subjects. J Hum Genet 53:174-180

7. Yamauchi T, Hara K, Maeda S et al (2010) A genome-wide association study in the Japanese population identifies susceptibility loci for type 2 diabetes at UBE2E2 and C2CD4A-C2CD4B. Nat Genet 42:864-868

8. Florez JC, Jablonski KA, Bayley N et al (2006) TCF7L2 polymorphisms and progression to diabetes in the Diabetes Prevention Program. N Engl J Med 355:241-250

9. Saxena R, Gianniny L, Burtt NP et al (2006) Common single nucleotide polymorphisms in TCF7L2 are reproducibly associated with type 2 diabetes and reduce the insulin response to glucose in nondiabetic individuals. Diabetes 55:2890-2895

10. Lyssenko V, Lupi R, Marchetti P et al (2007) Mechanisms by which common variants in the TCF7L2 gene increase risk of type 2 diabetes. J Clin Invest 117:2155-2163

11. Villareal DT, Robertson H, Bell GI et al (2010) TCF7L2 variant rs7903146 affects the risk of type 2 diabetes by modulating incretin action. Diabetes 59:479-485

12. Arce L, Yokoyama NN, Waterman ML (2006) Diversity of LEF/TCF action in development and disease. Oncogene 25:7492-7504

13. Hoppler S, Kavanagh CL (2007) Wnt signalling: variety at the core. J Cell Sci 120:385-393

14. Welters HJ, Kulkarni RN (2008) Wnt signaling: relevance to beta-cell biology and diabetes. Trends Endocrinol Metab 19:349-355

15. Murtaugh LC (2008) The what, where, when and how of Wnt/betacatenin signaling in pancreas development. Organogenesis 4:81-86

16. Jin $T$ (2008) The WNT signalling pathway and diabetes mellitus. Diabetologia 51:1771-1780

17. Dabernat S, Secrest P, Peuchant E, Moreau-Gaudry F, Dubus P, Sarvetnick N (2009) Lack of $\beta$-catenin in early life induces abnormal glucose homeostasis in mice. Diabetologia 52:1608-1617

18. Korinek V, Barker N, Moerer P et al (1998) Depletion of epithelial stem-cell compartments in the small intestine of mice lacking Tcf-4. Nat Genet 19:379-383

19. Boj SF, van Es JH, Huch M et al (2012) Diabetes risk gene and Wnt effector Tcf712/TCF4 controls hepatic response to perinatal and adult metabolic demand. Cell 151:1595-1607

20. Vacik T, Lemke G (2011) Dominant-negative isoforms of Tcf/Lef proteins in development and disease. Cell Cycle 10:4199-4200

21. Vacik T, Stubbs JL, Lemke G (2011) A novel mechanism for the transcriptional regulation of Wnt signaling in development. Genes Dev 25:1783-1795

22. Nguyen H, Merrill BJ, Polak L et al (2009) Tcf3 and Tcf4 are essential for long-term homeostasis of skin epithelia. Nat Genet 41:1068-1075

23. Terauchi Y, Takamoto I, Kubota N et al (2007) Glucokinase and IRS2 are required for compensatory beta cell hyperplasia in response to high-fat diet-induced insulin resistance. J Clin Invest 117:246-257

24. Kamei N, Tobe K, Suzuki R et al (2006) Overexpression of monocyte chemoattractant protein-1 in adipose tissues causes macrophage recruitment and insulin resistance. J Biol Chem 281:26602-26614

25. Kubota N, Kubota T, Itoh S et al (2008) Dynamic functional relay between insulin receptor substrate 1 and 2 in hepatic insulin signaling during fasting and feeding. Cell Metab 8:49-64 
26. Miyazaki J, Araki K, Yamato E et al (1990) Establishment of a pancreatic beta cell line that retains glucose-inducible insulin secretion: special reference to expression of glucose transporter isoforms. Endocrinology 127:126-132

27. Kubota N, Terauchi Y, Tobe K et al (2004) Insulin receptor substrate 2 plays a crucial role in beta cells and the hypothalamus. J Clin Invest 114:917-927

28. Matsui J, Terauchi Y, Kubota N et al (2004) Pioglitazone reduces islet triglyceride content and restores impaired glucose-stimulated insulin secretion in heterozygous peroxisome proliferator-activated receptor-gamma-deficient mice on a high-fat diet. Diabetes 53:2844-2854

29. Kikuchi O, Kobayashi M, Amano K et al (2012) FoxO1 gain of function in the pancreas causes glucose intolerance, polycystic pancreas, and islet hypervascularization. PLoS One 7:e32249

30. Norton L, Fourcaudot M, Abdul-Ghani MA et al (2011) Chromatin occupancy of transcription factor 7-like 2 (TCF7L2) and its role in hepatic glucose metabolism. Diabetologia 54:3132-3142

31. da Silva XG, Mondragon A, Sun G et al (2012) Abnormal glucose tolerance and insulin secretion in pancreas-specific Tcf712-null mice. Diabetologia 55:2667-2676

32. Kaneto H, Matsuoka TA, Kawashima S et al (2009) Role of MafA in pancreatic beta-cells. Adv Drug Deliv Rev 61:489-496

33. Hang Y, Stein R (2011) MafA and MafB activity in pancreatic beta cells. Trends Endocrinol Metab 22:364-373

34. Osmark P, Hansson O, Jonsson A, Ronn T, Groop L, Renstrom E (2009) Unique splicing pattern of the TCF7L2 gene in human pancreatic islets. Diabetologia 52:850-854

35. Le Bacquer O, Shu L, Marchand M et al (2011) TCF7L2 splice variants have distinct effects on beta-cell turnover and function. Hum Mol Genet 20:1906-1915

36. Locke JM, Da Silva XG, Rutter GA, Harries LW (2011) An alternative polyadenylation signal in TCF7L2 generates isoforms that inhibit $\mathrm{T}$ cell factor/lymphoid-enhancer factor (TCF/LEF)-dependent target genes. Diabetologia 54:3078-3082

37. Mao CD, Byers SW (2011) Cell-context dependent TCF/LEF expression and function: alternative tales of repression, de-repression and activation potentials. Crit Rev Eukaryot Gene Expr 21:207-236
38. Columbus J, Chiang Y, Shao W et al (2010) Insulin treatment and high-fat diet feeding reduces the expression of three Tcf genes in rodent pancreas. J Endocrinol 207:77-86

39. Savic D, Ye H, Aneas I, Park SY, Bell GI, Nobrega MA (2011) Alterations in TCF7L2 expression define its role as a key regulator of glucose metabolism. Genome Res 21:1417-1425

40. Yang H, Li Q, Lee JH, Shu Y (2012) Reduction in Tcf712 expression decreases diabetic susceptibility in mice. Int J Biol Sci 8:791-801

41. Oh KJ, Park J, Kim SS, Oh H, Choi CS, Koo SH (2012) TCF7L2 modulates glucose homeostasis by regulating CREB- and FoxO1dependent transcriptional pathway in the liver. PLoS Genet 8:e1002986

42. Shao W, Wang D, Chiang YT et al (2013) The Wnt signaling pathway effector TCF7L2 controls gut and brain proglucagon gene expression and glucose homeostasis. Diabetes 62:789-800

43. da Silva XG, Bellomo EA, McGinty JA, French PM, Rutter GA (2013) Animal models of GWAS-identified type 2 diabetes genes. J Diabetes Res 2013:906590

44. Merrill BJ, Pasolli HA, Polak L et al (2004) Tef3: a transcriptional regulator of axis induction in the early embryo. Development 131:263-274

45. Liu Z, Habener JF (2008) Glucagon-like peptide-1 activation of TCF7L2-dependent Wnt signaling enhances pancreatic beta cell proliferation. J Biol Chem 283:8723-8735

46. Ueki K, Okada T, Hu J et al (2006) Total insulin and IGF-I resistance in pancreatic beta cells causes overt diabetes. Nat Genet 38:583-588

47. Hashimoto N, Kido Y, Uchida T et al (2006) Ablation of PDK1 in pancreatic beta cells induces diabetes as a result of loss of beta cell mass. Nat Genet 38:589-593

48. Knop FK (2010) Comment on: Villareal et al (2009) TCF7L2 variant rs7903146 affects the risk of type 2 diabetes by modulating incretin action. Diabetes 59:479-485. Diabetes 59:e4; author reply e5-6

49. Gaulton KJ, Nammo T, Pasquali L et al (2010) A map of open chromatin in human pancreatic islets. Nat Genet 42:255-259

50. Shu L, Matveyenko AV, Kerr-Conte J, Cho JH, McIntosh CH, Maedler K (2009) Decreased TCF7L2 protein levels in type 2 diabetes mellitus correlate with downregulation of GIP- and GLP-1 receptors and impaired beta-cell function. Hum Mol Genet 18:2388-2399 